Contract No. and Disclaimer:

This manuscript has been authored by Savannah River Nuclear Solutions, LLC under Contract No. DE-AC09-08SR22470 with the U.S. Department of Energy. The United States Government retains and the publisher, by accepting this article for publication, acknowledges that the United States Government retains a non-exclusive, paid-up, irrevocable, worldwide license to publish or reproduce the published form of this work, or allow others to do so, for United States Government purposes. 
SRNL-STI-2010-00606

\title{
CRYOGENIC ADSORPTION OF HYDROGEN ISOTOPES OVER NANO-STRUCTURED MATERIALS
}

\author{
X. Xiao* and L. K. Heung \\ Savannah River National Laboratory, 999-2W, Savannah River Site, Aiken SC 29808 USA steve.xiao@srnl.doe.gov
}

\begin{abstract}
Porous materials such as zeolites, activated carbon, silica gels, alumina and a number of industrial catalysts are compared and ranked for hydrogen and deuterium adsorption at liquid nitrogen temperature. All samples show higher $\mathrm{D}_{2}$ adsorption than that of $\mathrm{H}_{2}$, in which a $\mathrm{HY}$ sample has the greatest isotopic effect while $13 \mathrm{X}$ has the highest hydrogen uptake capacity. Material's moisture content has significant impact to its hydrogen uptake. A material without adequate drying could result in complete loss of its adsorption capacity. Even though some materials present higher $\mathrm{H}_{2}$ adsorption capacity at full pressure, their adsorption at low vapor pressure may not be as good as others. Adsorption capacity in a dynamic system is much less than in a static system. A sharp desorption is also expected in case of temperature upset.
\end{abstract}

\section{INTRODUCTION}

Hydrogen adsorption at cryogenic temperature has wide potential applications in fusion technology development, ${ }^{3} \mathrm{He}$ purification and hydrogen isotope separation. Cryogenic adsorption is effective to completely remove low concentration of hydrogen isotopes from bulk helium gas. At low temperatures, many porous materials present isotopic effects that can be used to separate hydrogen isotopes.

The adsorption of zeolite has been well studied, ${ }^{1}$ largely in the petrochemical industry. Due to their crystalline structure, zeolites have uniformly nanostructured pores instead of a distribution of pore sizes such as in silica gel or activated carbon. Despite being well studied, information was scattered in pieces and sometimes confusing related to application in cryogenic adsorption. For example, the kinetic dimensions of zeolite pore opening and gas molecule diameter are temperature dependent. A 3A zeolite does not adsorb $\mathrm{H}_{2}$ molecules at liquid nitrogen temperature $\left(77 \mathrm{~K}\right.$ or $\left.-196^{\circ} \mathrm{C}\right)$ due to its pores being too small, while studies indicate that $\mathrm{H}_{2}$ adsorption takes place at $140 \mathrm{~K}$ or higher temperature. ${ }^{2}$ Similarly, a 4A zeolite does not adsorb $\mathrm{N}_{2}$ molecule at liquid nitrogen temperature, but significant adsorption was reported at $195 \mathrm{~K}\left(-78^{\circ} \mathrm{C}\right) .{ }^{1}$ Table 1 lists adsorption characteristics of various zeolites for commonly used adsorbents at liquid nitrogen temperature. The precision of pore diameter within a partial angstrom makes great difference for the exclusion of large gas molecules.

Table 1: Adsorption at Liquid Nitrogen Temperature

\begin{tabular}{l|cccc}
\hline & $\mathrm{H}_{2} \mathrm{O}$ & $\mathrm{N}_{2}$ & $\mathrm{H}_{2}$ & $\mathrm{Ar}$ \\
\hline $3 \mathrm{~A}$ & Yes & --- & --- & --- \\
$4 \mathrm{~A}$ & Yes & --- & Yes & --- \\
$5 \mathrm{~A}$ & Yes & Yes & Yes & Yes \\
$13 X$ & Yes & Yes & Yes & Yes \\
Activated Carbon & Yes & Yes & Yes & Yes \\
Alumina & Yes & Yes & Yes & Yes \\
Silica Gel & Yes & Yes & Yes & Yes \\
\hline
\end{tabular}

Recently natural mordenite was reported to have higher $\mathrm{H}_{2}$ and $\mathrm{D}_{2}$ uptakes than $5 \mathrm{~A}$ zeolite at liquid nitrogen temperature. ${ }^{3}$ The $\mathrm{H}_{2}$ uptake correlates with micropore surface area but not meso pores in various materials, ${ }^{4}$ in which an activated carbon sample with over $2,000 \mathrm{~m}^{2} / \mathrm{g}$ surface area adsorbed three times as much $\mathrm{H}_{2}$ as the best Zeolite. Langmuir (mono layer adsorption) constants were found well correlated with molecular weight of $\mathrm{H}$ and $\mathrm{D}$ hydrogen isotopes over various zeolites and activated carbons. ${ }^{5}$ Further, adsorption constants for $\mathrm{H}, \mathrm{D}$, and $\mathrm{T}$ hydrogen isotopes are all consistent with their respective molecular weights; only two of six species of hydrogen isotopes need to be obtained experimentally to predict all of them. ${ }^{6}$ Model expressions were developed for multi-component adsorption of 6 species of hydrogen isotopes on zeolite 5A and 13X (Ref. 7). The performance of a 5A zeolite bed for ITER application was found to be in agreement with the adsorption capacity measured by volumetric method. ${ }^{8}$ These studies have potential to improve existing technology such as ${ }^{3} \mathrm{He}$ purification, or to develop new technologies such as for isotope separation.

\section{EXPERIMENTAL}

Zeolite, activated carbon, silica gel, alumina and commercial catalyst samples were obtained from Zeolyst, UOP, Grace Davison, Sud-Chemie, Sasol and Sigma Aldrich. $\mathrm{H}_{2}$ and $\mathrm{D}_{2}$ adsorption isotherm data were collected using static-volumetric techniques at liquid 
nitrogen temperature with Micromeritics ASAP 2020 unit. The sample's BET surface area and porosity data were also collected from the same unit but using $\mathrm{N}_{2}$ as adsorbent. For convenience, most of $\mathrm{H}_{2}$ and $\mathrm{D}_{2}$ uptakes are compared at 800 torr vapor pressure. All samples were degassed for 10 hrs under vacuum or when it reached 4 umHg pressure prior to measurement. Additional cryogenic adsorption/desorption tests were also studied at flow-dynamic conditions using Micromeritics AutoChem II 2920 unit. The methods are commonly known as pulse chemical adsorption and temperature programmed desorption (TPD).

\section{RESULTS AND DISCUSSION}

\section{III.A. Effect of Moisture Level to $\mathrm{H}_{2}$ Adsorption}

The moisture content has significant impacts to the zeolite $\mathrm{H}_{2}$ adsorption capacity. Fig. 1 shows the relation between moisture level (or drying temperature) of a $4 \mathrm{~A}$ zeolite and its $\mathrm{H}_{2}$ uptake at liquid nitrogen temperature. Different color/shape data points represented different samples. Each sample was initially saturated with room moisture ( $>50 \% \mathrm{RH})$, then progressively dried from low to high temperatures under vacuum.

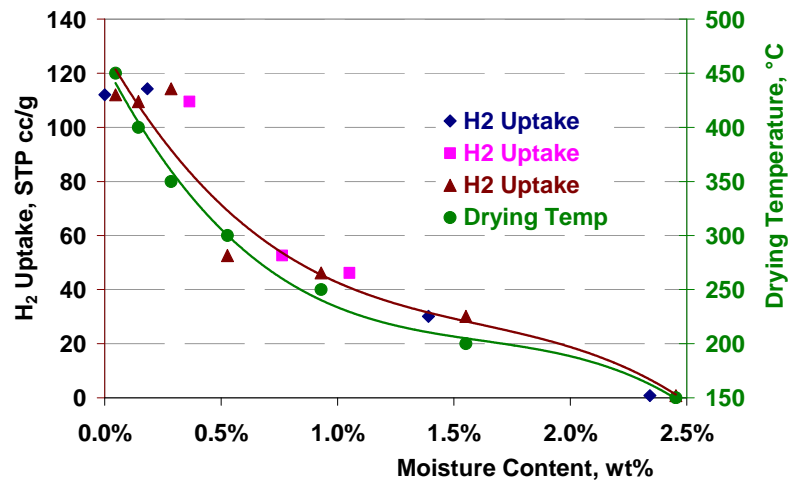

Fig. 1: Hydrogen Uptake as a Function of Sample Drying (4A Zeolite from Aldrich).

The moisture level as low as $0.5 \mathrm{wt} \%$ on zeolite would reduce the zeolite capacity to about half for $\mathrm{H}_{2}$ adsorption. At $2.3 \mathrm{wt} \%$ moisture (dried at $150^{\circ} \mathrm{C}$ ), the sample adsorbed only $0.8 \mathrm{scc} / \mathrm{g}_{2}$, comparing to 114 scc/g $\mathrm{H}_{2}$ when moisture was about $0.3 \mathrm{wt} \%$. When the sample was continuously dried above $350^{\circ} \mathrm{C}$, the $\mathrm{H}_{2}$ adsorption reached a plateau of 109-114 scc/g despite its weight loss continued. Note that the moisture content is based on sample weight relative to zeolite being dried at $450^{\circ} \mathrm{C}$ under vacuum (4 umHg). Based on the above study, all samples were dried at $350^{\circ} \mathrm{C}$ until reaching 4 um $\mathrm{Hg}$ vacuum for the following studies.

\section{III.B. $\mathrm{D}_{2}$ and $\mathrm{H}_{2}$ Adsorption Measurement Accuracy}

Since the difference between $\mathrm{H}_{2}$ and $\mathrm{D}_{2}$ adsorption is relatively small, measurement accuracy of adsorption isotherm was tested. Fig. 2 shows reproducibility of $\mathrm{D}_{2}$ and $\mathrm{H}_{2}$ adsorption/desorption isotherms over a UOP $13 \mathrm{X}$ Zeolite sample at liquid nitrogen temperature. The two $\mathrm{H}_{2}$ isotherms were almost identical, and the two $\mathrm{D}_{2}$ isotherms were almost identical, while the difference between $\mathrm{H}_{2}$ and $\mathrm{D}_{2}$ adsorption had a clear margin. The excellent precision of the instrument differentiated the small but real isotopic effect very well. Each respective adsorption and desorption curve overlapped completely without hysteresis. The $\mathrm{D}_{2}$ uptake was slightly higher than that of $\mathrm{H}_{2}$ in all pressure range.

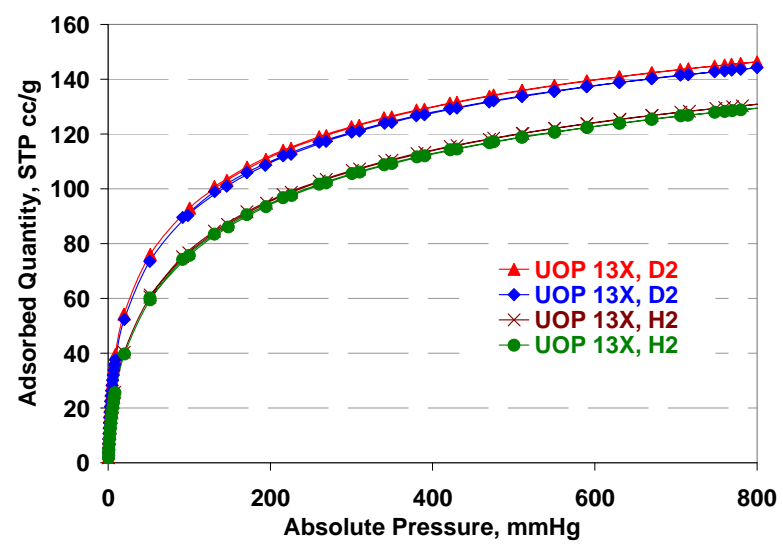

Fig. 2: Repeat $\mathrm{D}_{2} / \mathrm{H}_{2}$ Isotherms over UOP $13 \mathrm{X}$ Zeolite.

\section{III.C. Comparison of Adsorption Material Types}

Table 2 compares $\mathrm{H}_{2}$ and $\mathrm{D}_{2}$ adsorption quantity over various materials at liquid nitrogen temperature, along with each material's BET surface area measured by $\mathrm{N}_{2}$ adsorption. As expected, 3A zeolite did not adsorb hydrogen or deuterium, and 4A zeolite adsorbed hydrogen and deuterium but not nitrogen due to pore size restriction. The 4A, 5A, 13X zeolites and activated carbon all had over $100 \mathrm{scc} / \mathrm{g}$ of hydrogen uptake at 800 torr pressure, with $13 \mathrm{X}$ the most $\mathrm{H}_{2}$ uptake while activated carbon the greatest isotopic effect expressed as $\mathrm{D}_{2} / \mathrm{H}_{2}$ ratio. The performance of a Pd modified 4A zeolite was very similar to that of $4 \mathrm{~A}$. This is an indication of unchanged porosity. Due to ion exchange, the $\mathrm{Pd} / \mathrm{Z}$ is expected to have both $\mathrm{Pd}^{2+}$ and $\mathrm{Na}^{+}(4 \mathrm{~A})$ cations. Introduction of a nobel metal catalyzes hydrogen oxidation reaction for application in, e.g., tritium removal, and also converts HD with $\mathrm{H}_{2} / \mathrm{D}_{2}$, which is of interest for future study. Various commercial catalysts from Zeolyst and Sud-Chemie were also tested. All of them adsorbed higher amount of $\mathrm{D}_{2}$ than $\mathrm{H}_{2}$, of which a HY sample presented the highest $\mathrm{D}_{2} / \mathrm{H}_{2}$ ratio at $118 \%$. The quantity of hydrogen uptake was still good although lower than A 
and $\mathrm{X}$ types of zeolites. $\mathrm{X}$ and $\mathrm{Y}$ zeolites share the same framework structure but $\mathrm{Y}$ has higher $\mathrm{Si} / \mathrm{Al}$ ratio. The higher the $\mathrm{Si} / \mathrm{Al}$ ratio, the smaller the unit cell constant, thus slightly smaller the pores. The smaller pore of $\mathrm{Y}$ zeolite is likely responsible for higher isotopic effect, however, also decreases the hydrogen uptake to about a third of the value by 13X. Another sample with nobel metal and base metal modified ZSM-5 (Zeolyst Sample A) also showed good isotopic effect, at $115 \% \mathrm{D}_{2} / \mathrm{H}_{2}$ ratio. Different grades of silica gels presented isotopic effect comparable to zeolites but the hydrogen uptakes were much lower. The Sasol alumina sample adsorbed even smaller amount of hydrogen. Hydrogen is a noncondensing gas at liquid nitrogen temperature. The micropore portion was reported to be responsible for hydrogen adsorption, not mesopores or macro pores. ${ }^{4}$ The alumina sample has majority of mesopores with an average pore diameter of about $100 \AA$. It lacks the micropores to capture hydrogen molecules.

Table 2: Cryogenic Adsorption of Various Materials

\begin{tabular}{l|cccc}
\hline Material & $\begin{array}{c}\mathrm{BET} \\
\mathrm{m}^{2} / \mathrm{g}\end{array}$ & $\begin{array}{c}\mathrm{H}_{2} \\
\mathrm{scc} / \mathrm{g}\end{array}$ & $\begin{array}{c}\mathrm{D}_{2} \\
\mathrm{scc} / \mathrm{g}\end{array}$ & $\begin{array}{c}\mathrm{D}_{2} / \mathrm{H}_{2} \\
\text { ratio }\end{array}$ \\
\hline 3A MS, UOP & --- & 0.9 & 1.1 & --- \\
4A MS, UOP & --- & 113 & 121 & $107 \%$ \\
5A MS, UOP & 447 & 102 & 111 & $109 \%$ \\
13X MS, UOP & 592 & 131 & 140 & $107 \%$ \\
AC, Darco & 682 & 117 & 135 & $115 \%$ \\
$\begin{array}{l}\text { Pd/Z } \\
\text { Sud-Chemie ZeoSorb® }\end{array}$ & --- & 112 & 119 & $107 \%$ \\
T-2921 (Pt/Mord.) & 442 & 89.8 & 96.2 & $107 \%$ \\
Zeolyst CBV600 (HY) & 502 & 46.4 & 54.6 & $118 \%$ \\
Zeolyst Sample A (Noble & & & & \\
metal/Base metal /ZSM- & & & & \\
5) & 308 & 42.3 & 48.5 & $115 \%$ \\
Zeolyst Sample B (Noble & & & & \\
metal/Mord./ZSM-5) & 387 & 75.6 & 81.6 & $108 \%$ \\
Zeolyst Sample C (Noble & & & & \\
metal/Mord.) & 454 & 99.2 & 106 & $107 \%$ \\
Zeolyst CBV2314 (ZSM- & & & & \\
5) & 350 & 71.3 & 77.0 & $108 \%$ \\
SG, Davisil 646 & 316 & 23.3 & 24.9 & $107 \%$ \\
SG, Davisil 636 & 459 & 32.3 & 35.6 & $110 \%$ \\
SG, Merck 10181 & 595 & 37.9 & 42.7 & $113 \%$ \\
Alumina, Sasol 604130 & 204 & 15.4 & & ---
\end{tabular}

MS - zeolite (Molecular Sieve); AC - activated carbon; $\mathrm{SG}$ - silica gel; BET surface area based on $\mathrm{N}_{2}$ adsorption data; $\mathrm{H}_{2}$ and $\mathrm{D}_{2}$ uptake was at 800 torr, all at liquid nitrogen temperature.

\section{III.D. 4A Zeolites from Different Batches}

Table 3 shows some difference among 4A samples obtained from different vendors and lots on $\mathrm{H}_{2}$ and $\mathrm{D}_{2}$ adsorption data. The 4A zeolite sample from Aldrich (Lot\# 05529KH) was proven to double TCAP efficiency for $\mathrm{H}_{2}$ an $\mathrm{D}_{2}$ separation when used in an inverse column, ${ }^{9}$ while the sample's isotopic effect was the lowest among 4A samples compared. The result is encouraging since further improvements are very likely using samples with higher isotopic effects.

Table 3: Different Batches of 4A Zeolites

\begin{tabular}{|c|c|c|c|}
\hline 4A Zeolite & $\begin{array}{c}\mathrm{H}_{2} \\
\mathrm{scc} / \mathrm{g} \\
\end{array}$ & $\begin{array}{c}D_{2} \\
\mathrm{scc} / \mathrm{g} \\
\end{array}$ & $\begin{array}{l}D_{2} / \mathrm{H}_{2} \\
\text { ratio } \\
\end{array}$ \\
\hline $\begin{array}{l}\text { 4A MS, Grace Davison } \\
\text { Lot\#1000103855 } \\
\text { 4A MS, UOP }\end{array}$ & 115.2 & 128.9 & 111 \\
\hline Lot\#2 & 107.9 & 120.4 & \\
\hline $\begin{array}{l}\text { Lot\#2007009256* } \\
\text { 4A MS, Aldrich } 334308 \text { Lot }\end{array}$ & 113.2 & 121.4 & 107.3 \\
\hline 05529KH & 114.5 & 116.9 & $102.1^{\prime}$ \\
\hline
\end{tabular}

\section{III.D. Low Pressure vs. Full Pressure $\mathrm{H}_{2}$ Adsorption}

Fig. 3 compares $\mathrm{H}_{2}$ adsorption/desorption isotherms at liquid nitrogen temperature for 4A, 5A, 13X zeolites and activated carbon. All samples had significant $\mathrm{H}_{2}$ adsorption. The isotherms indicated that $13 \mathrm{X}$ zeolite adsorbed 30\% more $\mathrm{H}_{2}$ than 5A zeolite (131 vs. 102 scc/g). However, a closer look of the "zoom-in" of low pressure range indicated that the isotherm slope of $13 \mathrm{X}$ is not as steep as that of "A" type zeolites, as seen in Fig. 4. The 4A zeolite has the steepest slope of low pressure $\mathrm{H}_{2}$ adsorption, followed by $5 \mathrm{~A}$ zeolite and activated carbon. At 0.5 torr vapor pressure, for example, $13 \mathrm{X}$ zeolite only adsorbed 3.4 scc $\mathrm{H}_{2}$ /g while 4A, 5A and activated carbon adsorbed about $7.3 \mathrm{scc} \mathrm{H}_{2} / \mathrm{g}$. On the other hand, at $5 \mathrm{scc}$ $\mathrm{H}_{2} / \mathrm{g}$ adsorption, the vapor pressure of $13 \mathrm{X}$ is then 0.75 torr comparing to 0.3 torr for other materials. The comparison at low pressure is important for trace tritium removal such as in ${ }^{3} \mathrm{He}$ purification or radio active material confinement processes, while full pressure uptake is related to the material capacity for hydrogen isotope as a major component.

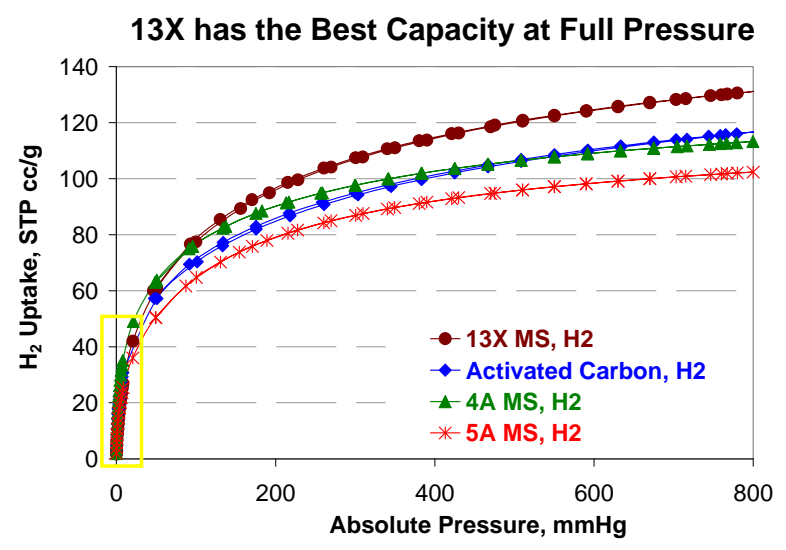

Fig. 3: $\mathrm{H}_{2}$ Adsorption Isotherm Comparison. 


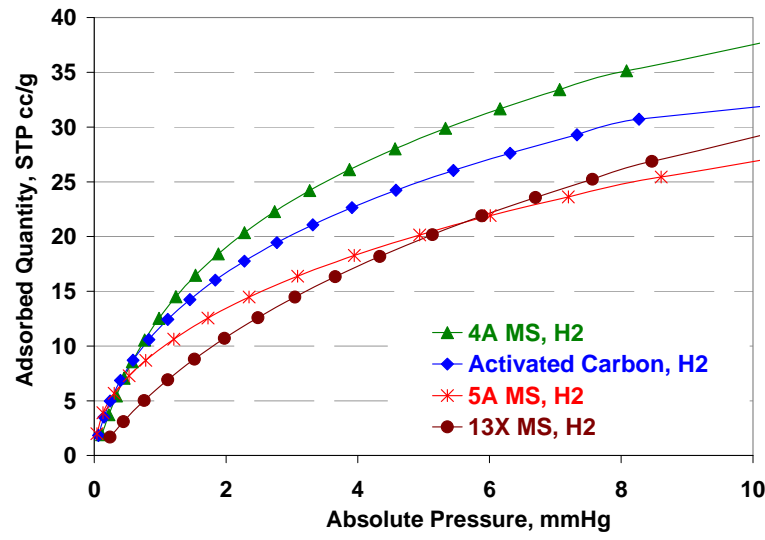

Fig. 4: Low Pressure $\mathrm{H}_{2}$ Adsorption Isotherm.

\section{III.E. Flow Dynamic Adsorption and Desorption}

The Darco activated carbon was tested with $\mathrm{H}_{2}$ pulse chemi adsorption followed by desorption with temperature increases. As seen in Fig. 5, breakthrough started at about 30 minutes after 7 doses were completely adsorbed. Additional doses resulted in continuous ramp of hydrogen concentration, as opposed to individual peaks normally observed at ambient conditions. The pulse chemi was stopped after 15 total doses, in which the sample had a cumulative adsorption of $55.5 \mathrm{scc} / \mathrm{g}$. This was less than $117 \mathrm{scc} / \mathrm{g}$ from static measurement at 800 torr, because hydrogen partial pressure is lower in a flow dynamic system. When the liquid nitrogen Dewar was removed, $\mathrm{H}_{2}$ desorbed immediately with a sharp peak at 3 minutes $\left(-78^{\circ} \mathrm{C}\right)$, followed by a smaller peak at 6 minutes $\left(-18^{\circ} \mathrm{C}\right)$. The desorption signal after 45 minutes was due to initial sample dry out at $350^{\circ} \mathrm{C}$.

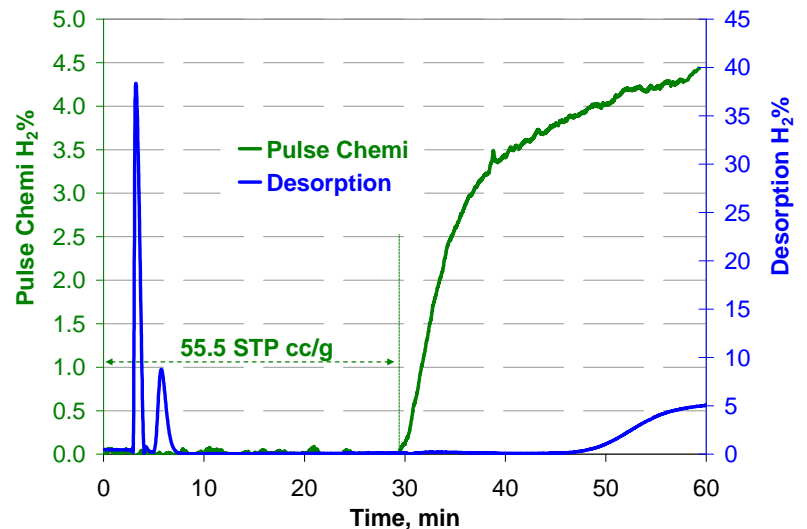

Fig. 5: Cryogenic Pulse Chemi and Desorption of Darco Activated Carbon.

\section{CONCLUSIONS}

Porous materials such as zeolites, activated carbon, silica gels, alumina and a number of industrial catalysts all show higher than unity $\mathrm{D}_{2} / \mathrm{H}_{2}$ isotopic effect at liquid nitrogen temperature, in which a $\mathrm{HY}$ sample has the greatest isotopic effect while a $13 \mathrm{X}$ has the highest hydrogen uptake. A material without adequate drying could result in complete loss of its $\mathrm{H}_{2}$ adsorption capacity. Material presenting higher $\mathrm{H}_{2}$ adsorption capacity at full pressure may not be a good candidate at low pressure. Adsorption capacity in a dynamic system is less than in a static system. The same type of material from different vendors or lots may behave differently.

\section{ACKNOWLEDGMENTS}

This paper was prepared in conjunction with work accomplished under Contract No. DE-AC09-08SR22470 with the U.S. Department of Energy. Special thanks to Beverly Morrell for her diligent laboratory support.

\section{REFERENCES}

1. D.W. Breck (Editor), "Zeolite Zeolites: Structure, Chemistry and Use", John Wiley \& Sons Inc; 3rd Print edition, ISBN: 0471099856, (1974).

2. K. Kotoh, S. Takashima, Y. Nakamura, "Molecularsieving effect of zeolite 3A on adsorption of $\mathrm{H}_{2}$, HD and $\mathrm{D}_{2}$ ”, Fusion Engineering and Design 84 (2009) 1108-1112.

3. K. Munakata, T. Takeishi, S. Kajii, T. Wajima, Y. Kawamura, "Adsorption of Hydrogen Isotopes on Various Adsorbents at Cryogenic Temperature", Fusion Science and Technology, Vol. 56, 153, (2009).

4. M.G. Nijkamp, J.E.M.J. Raaymakers, A.J. van Dillen, K.P. de Jong, "Hydrogen Storage using Physisorption -Materials Demands”, Appl. Phys. A 72, 619-623, (2001).

5. M. Nishikawa, K. Tanaka, M. Uetake, T. Shiraishi, "Isotope Effect in Cryosorption of Tritium to Zeolites and Activated Carbon at 77K”, Fusion Technology, Vol. 34, 234, (1998).

6. Y. Kawamura, M. Enoeda, "Adsorption Isotherms for Tritium on Various Adsorbent at Liquid Nitrogen Temperature”, Fusion Technology, Vol. 37, 54, (2000).

7. K. Kotoh, K. Kudo, "Multi-Component Adsorption Behavior of Hydrogen Isotopes on Zeolite 5A and 13X At 77.4 K”, Fusion Science and Technology, Vol. 48, 148, (2005).

8. S. Beloglazov, N. Bekris, M. Glugla, R. Wagner, "Semi-Technical Cryogenic Zeolite Bed for the Tritium Extraction System of the Test Blanket 
Module for ITER", Fusion Science and Technology, Vol. 48, 662, (2005).

9. L. K. Heung, H. T. Sessions, and X. Xiao, "TCAP Hydrogen Isotope Separation using Palladium and Inverse Columns”, Fusion Science and Technology, submitted (2010). 